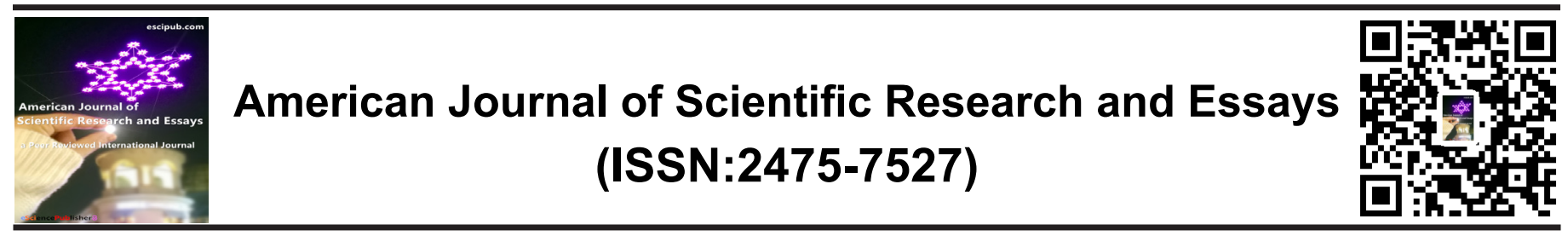

\title{
Adsorption Kinects and Isotherms for Removal of Rhodamine B (dye) using Adsorbents prepared from drinking water treatment sludge
}

\author{
M.Nageeb Rashed*1, M.A.El-Daim El Taher1, S. M. M. Fadlalla2 \\ 1.Chemistry Department, Faculty of Science, Aswan University, Egypt \\ 2. Aswan Company for Water and Wastewater, Aswan, Egypt
}

\begin{abstract}
The present work aims to investigate the removal of Rhodamine $B$ dye (RB) from aqueous solution by using adsorbents prepared from alum sludge (AS) and Mud sludge (MS) of drinking water treatment plant. The effect of dye concentration, contact time, $\mathrm{pH}$, temperature and adsorbent dose on the dye removal was studied. The equilibrium adsorption data of RB dye on the developed adsorbents were analyzed by the Langmuir, Freundlich, Temkin and Dubinin-Radushkevich (D-R) Isotherms. The sorption data fitted well to Langmuir isotherm model. The maximum dye removal efficiency was observed at $\mathrm{pH} 7$, contact time 90 min,and 0.1-0.25 gm dosage for both (AS) and (MS) adsorbents . Also, four kinetic models such as Pseudo-first order, Pseudo-second order, Intraparticle diffusion and Elovich models were tested to interpret the experimental data. The kinetic experimental data were fitted well to Pseudo-second order model. The thermodynamics parameters of adsorption system indicated spontaneous and endothermic process. Results indicate the effectiveness of the developed adsorbents for removing RB dye.
\end{abstract}

\section{Key words:}

Sweage sludge, Rhodamine B, adsorption, pollution, wastewater.
*Correspondence to Author:

M.Nageeb Rashed, Chemistry Department, Faculty of Science, Aswan University, 81528 Aswan, Egypt. E-mail: mnrashed @hotmail.com

How to cite this article:

Rashed et al. Adsorption Kinects and Isotherms for Removal of Rhodamine B (dye) using Adsorbents prepared from drinking water treatment sludge. American Journal of Scientific Research and Essays, 2016,1(1): 0013-0030.

\section{eSciencePublisher}

eSciPub LLC, Houston, TX USA. Website: http://escipub.com/ 


\section{Introduction}

Dyes are chemicals that may be harmful and on binding with a material will give color to them. New dyes are synthesized and have several applications as they are gorgeously colorful. Textile is one of those industries where more and more dyes and pigments are used to color the products. In recent years, it is estimated that more than 100,000 dyes are available commercially (Lee and Choi, 2006) and their global production exceeds 800,000 tons per year (Bouasla et al.,2010) .The colored dye effluents are generally considered to be highly toxic to the aquatic system. Some dyes are reported to cause skin irritation, dermatitis, allergy and cancer in humans (Salleh, et al ., 2011) .

Industrial wastewater, contain dyes, is usually treated by physical and chemical methods such as sonochemical degradation (Abbasi and ASI, 2008) , photochemical degradation (Gupta et al. , 2007) , electrochemical degradation (Fan etal., 2008), coagulation and flocculation (Zonoozi et al.,2009), membrane separation (Sachdeva and Kumar ,2009), activated carbon adsorption ( Tan et al.,2008) and oxidation or ozonation (Malik and Saha, 2003) . However, in developing countries, these methods are still too expensive to be used widely. Developing economical adsorbents for dye treatment of industrial wastewater has attracted a great interest in recent years. Recently, the application of low -cost adsorbents for the dye removal has been reviewed (Bhatnagar and Sillanppa ,2010)

Rhodamine-B (RB) is one of the water soluble xanthenes class dyes, a basic red cationic dye which is a common water tracer fluorescent. It is often used in textile, silk, wool, cotton, and food industries. It is potentially harmful to humans as it can cause eye burn, irritation to the skin, gastrointestinal and the respiratory tracts. For these reasons, the treatment of dye effluents is essential prior to their discharge into the receiving water bodies (Arivoli and Thenkuzhali ,2009).

The cost is actually an important parameter for comparison and selection of adsorbents. The literature survey reveals that there has been numerous researchs reported the using of low cost adsorbents for dye removal, which are economical viable, easily available, highly effective in the adsorption process (Chamargore et al., 2010). Low-cost adsorbents have been studied for the removal of dyes and heavy metals from wastewater such as waste apricot (Sun and Yang , 2003), coconut shell (Kumar and Porkodi ,2007), dairy sludge (Gong et al., 2005), bamboo grass treated with concentrated sulfuric acid (Sumanjit and Prasad ,2001), peat (Sumanjit et al.,2010), bamboo(Ma et al.,2010), jack fruit peels (Jai and Jayaram ,2007), pistachio nut shells (Vijayalakshmi et al.,2011), date stone and palm tree waste (Belala et al., 2011), treated sewage sludge(Rashed et al., 2011), and phosphate slime (Rashed et al.,2015).

Alum and mud sludges are by-product from the processing of drinking water in drinking water treatment plants. Alum sludge produced when alum (aluminium sulfate) is used as coagulant. Mud sludge also by-product but when the quality of raw water is high and not needs to alum. The disposal of these sludge to a landfill environmental problems; since alum sludge contains a high level of aluminium, which has been shown to be toxic to aquatic life and relatively inert, providing marginal benefits to soil fertility Moreover, the reuse of alum and mud sludge will be economically and environmentally beneficial .

Researches have shown that drinking water treatment sludge (Alum sludge) can be used as an effective adsorbent for phosphate (Yang et al., 2006; Al-Fatlawi and Neamah, 2015), and some heavy metals (Zhou and Haynes, 2010; Lee et al., 2006 ) but no researches has discussed its use as a Rhodamine-B dye adsorbent. It is noted from the literature that alum or mud sludge adsorbents has not investigated for Rhodamine-B dye removal.

The purpose of this study is to investigate the adsorption behavior of alum and mud sludge adsorbents for Rhodamine-B dye removal from polluted solution. The adsorption equilibrium, kinetics, isotherms, and thermodynamics studies were then studied to observe the effects of various process parameters such as initial dye concentrations, contact time, $\mathrm{pH}$, dose, and temperature on Rhodamine-B dye removal.

\section{Materials and methods}

\subsection{Sample collection.}


Alum sludge and mud sludge were used as raw materials for preparation of adsorbent in the study. Mud sludge was obtained from Gabal Takok drinking water treatment plant at Aswan City, while and Alum sludge was obtained from Fatera drinking water treatment plant at Kom Ombo city, Aswan governorate, Egypt. The sludge samples were air dried in a clean place and crashed into uniform $0.2 \mathrm{~mm}$ size, then oven dried at $105^{\circ} \mathrm{C}$ for $24 \mathrm{~h}$,cooled, and kept in the desiccators until used. The physico-chemical characteristics of Alum and Mud sludge are summarized in Table (1).

\subsection{Preparation of Sludge (Alum and Mud) Adsorbents by Physical Activation:}

Alum and mud adsorbents were obtained by physical and chemical activation as described previously in our published paper ( Rashed et al. 2016). Based on the previous study, in physical activation of alum and mud sludge ,100 gm of dry sludge was pyrolized at 400, 500, 600, 700, 800 , and $900^{\circ} \mathrm{C}$ for one hour. The resulted adsorbents are AS400, AS500, AS600, AS700, AS800, and AS900 for alum sludge adsorbent ,and MS400, MS500, MS600, MS700, MS800, and MS900 for mud sludge adsorbent.

\subsection{Preparation of Sludge (Alum and Mud) Adsorbents by Chemical Activation:}

Chemical activation of alum and mud sludges were preceded by three methods as described in our published paper ( Rashed et al. 2016) as follows:

\subsubsection{Activation with Acetic Acid $\left(\mathrm{CH}_{3} \mathrm{COOH}\right)$}

$10 \mathrm{gm}$ of dry sludge was mixed with $100 \mathrm{ml}$ of each acetic acid concentration $(0.1,0.5,1,2$ and $3 \mathrm{M}$ ), stirred at $60^{\circ} \mathrm{C}$ for four hours, filtered, washed with deionized water, and dried at $120^{\circ}$ $\mathrm{C}$ for 12 hours. The dried residue was pyrolized in the oven at $500^{\circ} \mathrm{C}$ for two hours, and left in the desiccators for further use. The developed alum sludge adsorbents labeled AS1 (0.5 M AA), AS1( 1 M AA) , AS1(2M AA) and AS1(3M AA) for treatment with $0.1,0.5,1,2$ and $3 \mathrm{M}$ acetic acid, respectively. The developed mud sludge adsorbents labeled MS1 (0.1 M AA), MS1(0.5 M $\mathrm{AA}$ ), MS1(1 MAA) and MS1(2 M AA) and MS1(3 $\mathrm{M} \mathrm{AA}$ ) for treatment with $0.1,0.5,1,2$ and $3 \mathrm{M}$ acetic acid, respectively(Rashed et al., 2016).

\subsubsection{Activation of Alum and Mud Sludge with Acetic Acid followed by pyrolysis.}

Sludge sample was mixed with water to yield the moisture content of $20 \%$. The sludge pellet form was made by cutting it to a uniform size of 2-2.5 $\mathrm{mm}$. Pellets were heated in an oven at $500^{\circ} \mathrm{C}$ for 2 hours. Pellets (10 gm ) was mixed with 100 $\mathrm{ml}$ of each acetic acid concentration $(0.1,0.5$, 1,2 , and $2 \mathrm{M}$ ) and stirred at $60^{\circ} \mathrm{C}$ for $4 \mathrm{~h}$. The sample was dried at $120^{\circ} \mathrm{C}$ for 12 hours, after that left in desiccators for use. The developed alum sludge adsorbents labeled AS2 (0.1M AA) , AS2(0.5 M AA) , AS2( 1 M AA), AS2 (2M AA) and AS2 (3M AA) for treatment with $0.1,0.5,1,2$ and $3 \mathrm{M}$ acetic acid, respectively. The developed mud sludge adsorbents labeled MS2 (0.1M AA), MS2(0.5 M AA), MS2 ( 1 M AA), MS2 (2M AA) and MS2 (3M AA) for treatment with $0.1,0.5,1$, 2 and $3 \mathrm{M}$ acetic acid, respectively(Rashed et al., 2016).

\subsubsection{Activation of Alum and Mud Sludge with Nitric Acid}

The dried sludge sample $10 \mathrm{gm}$ was mixed with $50 \mathrm{ml}$ of each $\mathrm{HNO}_{3}$ concentrations $(0.25,0.5,1$, and $2 \mathrm{M}$ ), filtered and left for 24 hours. After that it washed with deionized water, dried at $60^{\circ} \mathrm{C}$ in an oven for $24 \mathrm{~h}$ and left in desiccators for further use. The developed alum sludge adsorbents labeled AS3 (0.25M NA), AS3 (0.5 M NA), AS3( $1 \mathrm{M} \mathrm{NA})$ and $A S 3(2 \mathrm{M} \mathrm{NA})$ for treatment with $0.25,0.5,1$ and $2 \mathrm{M}$ nitric acid, respectively. The developed mud sludge adsorbents labeled MS3 (0.25M NA) , MS3(0.5 M NA), MS3( 1 M NA) and MS3(2M NA) for treatment with $0.25,0.5,1$ and $2 \mathrm{M} \mathrm{HNO} 3$, respectively .

All the developed adsorbents were ground in an agate mortar and sieved to particle size63 $\mu \mathrm{m}$. The resulted adsorbents were successfully characterized by XRF, XRD, and SEM as mentioned previously in our published paper (Rashed et al.2016) .

\section{Analytical Measurement}

The initial and residual Rhodamine-B dye concentration in the aqueous solution was analyzed using UV-Vis spectrophotometer (model Thermo Scientific Nicolet evolution 100). 
Rashed et al., AJSRE, 2016; Vol. 1(1): 0013-0030

Table (1). The physico-chemical characteristics of Alum and Mud sludge.

\begin{tabular}{|c|c|c|}
\hline Properties & Alum Sludge & Mud Sludge \\
\hline Moisture content \% & 10.95 & 9.86 \\
\hline Ash \% & 6.88 & 5.85 \\
\hline Volatile matter \% & 5.5 & 5.33 \\
\hline Matter soluble in water \% & 0.81 & 0.56 \\
\hline Matter soluble in 0.25 M HCl \% & 3.09 & 2.9 \\
\hline Bulk density, gmL $^{-1}$ & 0.142 & 0.139 \\
\hline Specific gravity & 1.009 & 1.004 \\
\hline
\end{tabular}

Table (2). Removal percent of Rhodamine B by chemically activated adsorbents (AS \&MS) using acetic acid and acetic acid with pyrolysis at $500^{\circ} \mathrm{C}$

\begin{tabular}{|c|c|c|c|c|}
\hline \multicolumn{2}{|c|}{ Activation by acetic acid (AA) and pyrolysis } & \multicolumn{2}{c|}{ Activation by acetic acid } \\
\hline & AS & MS & AS & MS \\
\cline { 2 - 5 } AA Concentration (M) & Removal\% & Removal\% & Removal\% & 72.9 \\
\hline 0.1 & 48.9 & 69.6 & 80.6 & 77.8 \\
0.5 & 50.8 & 58.6 & 70.2 & 62.2 \\
1 & 57.4 & 55.2 & 69.8 & 54.6 \\
2 & 65.5 & 52.7 & 60.2 & 45.4 \\
\hline
\end{tabular}

Table (3). Removal percent of Rhodamine B by chemically activated adsorbents (AS \&MS) with nitric acid .

\begin{tabular}{|c|c|c|}
\hline \multicolumn{2}{|c|}{ Activation by nitric acid (NA) } \\
\hline \multirow{2}{*}{ NA Concentration (M) } & AS & MS \\
\cline { 2 - 3 } & Removal\% & 92 \\
0.25 & 95.2 & 78.6 \\
1 & 83.5 & 72.9 \\
2 & 75.4 & 58.7 \\
\hline
\end{tabular}


Rashed et al., AJSRE, 2016; Vol. 1(1): 0013-0030

Table (4). Removal percent of Rhodamine B by physically activated adsorbents (AS \&MS).

\begin{tabular}{|c|c|c|}
\hline \multirow{2}{*}{ Activator $^{\circ} \mathrm{C}$} & Physically activated sludge & MS \\
\cline { 2 - 3 } & Removal\% & Removal\% \\
\hline 500 & 58.5 & 54.9 \\
600 & 60.9 & 58.6 \\
700 & 66.1 & 60.2 \\
800 & 87.8 & 83.7 \\
900 & 55.7 & 50.8 \\
\hline
\end{tabular}

Table (5): Removal percentage (\%) of RB dye on alum and mud sludge adsorbents according to initial RB dye concentration.

\begin{tabular}{|l|l|l|l|l|l|l|l|l|}
\hline \multirow{2}{*}{$\begin{array}{l}\text { RhB Con. } \\
(\mathrm{ppm})\end{array}$} & \multicolumn{4}{|c|}{ AS adsorbent } & \multicolumn{5}{c|}{ MS Adsorbent } \\
\cline { 2 - 9 } & AS1 & AS2 & AS3 & AS700 & MS1 & MS2 & MS3 & MS700 \\
\hline 50 & 73.09 & 81.78 & 94.57 & 88.9 & 69.55 & 77.58 & 90.45 & 84.23 \\
\hline 60 & 69.72 & 75.1 & 84.1 & 78.1 & 60.2 & 69.81 & 82.5 & 75.8 \\
\hline 70 & 61.7 & 65.4 & 72.3 & 70 & 55.29 & 62.33 & 69.5 & 66.9 \\
\hline 100 & 50.5 & 54.8 & 62.1 & 58 & 47.2 & 52.3 & 60.2 & 56.14 \\
\hline
\end{tabular}

Table 6. Results of isotherm plots for adsorption of Rhodamine B dye onto Alum and Mud Sludge Adsorbents.

\begin{tabular}{|c|c|c|c|c|c|c|c|c|}
\hline Parameters & AS1 & AS2 & AS3 & AS4 & MS1 & MS2 & MS3 & MS4 \\
\hline \multicolumn{9}{|c|}{ Langmuir Isotherm model } \\
\hline Q0 & 23.365 & 24.096 & 25.641 & 24.69 & 22.727 & 23.697 & 25.707 & 27.55 \\
\hline $\mathrm{b}_{\mathrm{L}}(\mathrm{L} / \mathrm{mg})$ & 0.131 & 0.203 & 0.4722 & 0.307 & 0.0859 & 0.1461 & 0.3473 & 0.1464 \\
\hline $\mathrm{R}^{2}$ & 0.9995 & 0.9979 & 0.9929 & 0.9963 & 0.988 & 0.9973 & 0.9962 & 0.9854 \\
\hline \multicolumn{9}{|c|}{ Freundlich Isotherm model } \\
\hline $1 / \mathrm{n}$ & 0.239 & 0.1805 & 0.0965 & 0.1346 & 0.257 & 0.2098 & 0.138 & 0.1692 \\
\hline$K_{f}\left(m g^{-1 / n} L^{1 / n} g^{-1}\right)$ & 8.113 & 10.995 & 16.765 & 13.804 & 6.707 & 9.262 & 14.421 & 11.74 \\
\hline $\mathrm{R}^{2}$ & 0.9517 & 0.9976 & 0.8874 & 0.9438 & 0.9411 & 0.9939 & 0.9832 & 0.9895 \\
\hline \multicolumn{9}{|c|}{ Temkin Isotherm model } \\
\hline$B(\mathrm{j} / \mathrm{mol})$ & 4.1589 & 3.4315 & 2.0781 & 2.7274 & 4.1579 & 3.79 & 2.8945 & 3.2907 \\
\hline $\mathrm{b}_{\mathrm{T}}$ & 595.73 & 722.009 & 1192.23 & 908.401 & 595.871 & 653.713 & 855.959 & 752.901 \\
\hline Kt (L/g) & 2.778 & 12.648 & 2492.397 & 101.286 & 1.639 & 5.011 & 97.115 & 19.31 \\
\hline$R^{2}$ & 0.9702 & 0.9946 & 0.8611 & 0.9327 & 0.9325 & 0.988 & 0.9696 & 0.9805 \\
\hline \multicolumn{9}{|c|}{ Dubin-Raduskevich Isotherm model } \\
\hline $\mathrm{q}_{\mathrm{m}}(\mathrm{mg} / \mathrm{g})$ & 20.357 & 20.953 & 22.314 & 21.445 & 17.95 & 20.001 & 22.461 & 21.096 \\
\hline $\mathrm{E}(\mathrm{kj} / \mathrm{mol})$ & 0.224 & 0.3536 & $1 . .291$ & 0.707 & 0.224 & 0.289 & 0.7071 & 0.408 \\
\hline $\mathrm{R}^{2}$ & 0.9856 & 0.8529 & 0.5138 & 0.6219 & 0.7165 & 0.8185 & 0.7178 & 0.7597 \\
\hline $\mathrm{K}\left(\mathrm{mol}^{2} / \mathrm{J}^{2}\right)$ & $1 * 10^{-5}$ & $4 * 10^{-6}$ & $3 * 10^{-7}$ & $1 * 10^{-6}$ & $1 * 10^{-5}$ & $6 * 10^{-6}$ & $1 * 10-6$ & $3 * 10^{-6}$ \\
\hline
\end{tabular}


Rhodamine-B dye standard calibration curve was obtained by recording the absorbance values of various concentrations of Rhodamine-B dye at the maximum absorbance of wavelength 543 $\mathrm{nm}$.

\subsection{Adsorbate}

Rhodamine-B dye [chemical formula $\mathrm{C}_{28} \mathrm{H}_{31} \mathrm{CIN}_{2} \mathrm{O}_{3}, \mathrm{MW}$ 479.01]. The stock solution (1000 ppm) of Rhodamine-B dye is prepared by dissolving $1 \mathrm{gm}$ of RhB in $1000 \mathrm{ml}$ of double distilled water.

\subsection{Adsorption Studies}

Adsorpion experiments were performed at room temperature of $25{ }^{\circ} \mathrm{C}, 100 \mathrm{ml}$ of 50 ppm concentration $\mathrm{RhB}$ dye and solution $\mathrm{pH}$ maintained natural, as well as desire done when needed likewise the other parameters such as adsorbent doses, temperature , and contact time were also either varied or kept at the desired level as per the need. All sample solution was filtered through Goch. The $\mathrm{pH}$ of the dye solution was adjusted by using $0.1 \mathrm{M}$ of $\mathrm{NaOH}$ or $\mathrm{HCl}$ solution. Experiments were carried out twice and the concentrations given were average values. The equilibrium concentrations of RhB dye after adsorption was measured by UV spectrophotometer.

The percentage removal of RB dye was calculated by the following equation

$$
\% \mathrm{R}=\left[\left(\mathrm{C}_{\mathrm{o}}-\mathrm{Ce}\right) / \mathrm{C} 0\right] * 100
$$

The amount of RB dye adsorbed per unit mass of the adsorbent was evaluated by using the following equation, qe $(\mathrm{mg} / \mathrm{g})$

$$
q e=\left(C_{0}-\mathrm{Ce} / \mathrm{m}\right) \mathrm{V}
$$

Where $\quad C_{0}=$ Initial concentration of dye $(\mathrm{mg} / \mathrm{l})$

$\mathrm{Ce}=$ the equilibrium concentration $(\mathrm{mg} / \mathrm{l})$

$\mathrm{V}=$ the volume of dye solution $(\mathrm{L})$

$\mathrm{m}=$ the mass of adsorbent $(\mathrm{g})$

\section{Results and Discussion}

\subsection{FTIR analysis of Alum and Mud Sludge Adsorbents and dye loaded Adsorbent}

To confirm the adsorption of RhB dye on AS and MS adsorbents, FTIR spectra was applied for both the developed sludge adsorbents (AS \& MS) ) and dye loaded adsorbents. The FT-IR spectra of the samples were recorded through an FTIR spectrometer using KBr tablets (JASCO 3600 Tokyo, Japan) at room temperature in the range $400-4000 \mathrm{~cm}^{-1}$.

\subsubsection{FTIR analysis of Alum Sludge adsorbent (AS) and dye loaded adsorbents.}

The FTIR spectra of AS adsorbent and dye loaded AS were presented in Fig 1 . FTIR spectra of alum sludge adsorbent (AS) showed broadband $1041 \mathrm{~cm}^{-1}$ that were assigned to the most intense Si-O stretching modes.

Peaks characteristic broadband appeared at $3433.64 \mathrm{~cm}^{-1}$ correspond to the presence of $\mathrm{OH}$ stretching vibration due to the extinction of surface hydroxyl group and chemisorbed $\mathrm{H}_{2} \mathrm{O}$ , while the absorption band present at 2929$2972 \mathrm{~cm}^{-1}$ may suggest the presence of organic carbon These bands are due to $\mathrm{C}-\mathrm{H}$ absorption contaminants present in the sample. It can be inferred that the alkane groups do play a significant role in adsorption as their adsorption peak $2929.34 \mathrm{~cm}^{-1}$ characteristic of carbon-and hydrogen containing species, with double bond and are assigned to various forms of $\mathrm{C}-\mathrm{H}$ stretching, and $\mathrm{CH}_{2}$ alkene. The presence of quartz in the samples the observation of the peaks in the ranges 463 - 465 and 529 - 533 $\mathrm{cm}^{-1}$. Calcite is the most common carbonate mineral in natural samples the existence of peak at $1425 \mathrm{~cm}^{-1}$. The peaks at $460-465 \mathrm{~cm}^{-1}$ indicate the presence of microcline.After RhB dye adsorption, peak shifted to $2972.73 \mathrm{~cm}^{-}$ 1 , while peak at $2364.3 \mathrm{~cm}^{-1}$ characteristic of carbon-and hydrogen containing species with single bond and are assigned to various forms of C-H stretching. Also, dye loaded AS shifted to $2372.73 \mathrm{~cm}^{-1}$. The presences of these groups are responsible for adsorption of $\mathrm{RhB}$ dye onto the Alum Sludge adsorbent, AS ,surface.

\subsubsection{FTIR analysis of Mud Sludge adsorbent (MS) and dye loaded adsorbent.}

FT-IR spectrum of Mud Sludge adsorbent (MS) in Fig ( 2 ) which showed a wide band with maximum peak at $3438.46,3432.67 \mathrm{~cm}^{-1}$. This band can be assigned to the $\mathrm{O}-\mathrm{H}$ stretching mode of hydroxyl groups and adsorbed water. 


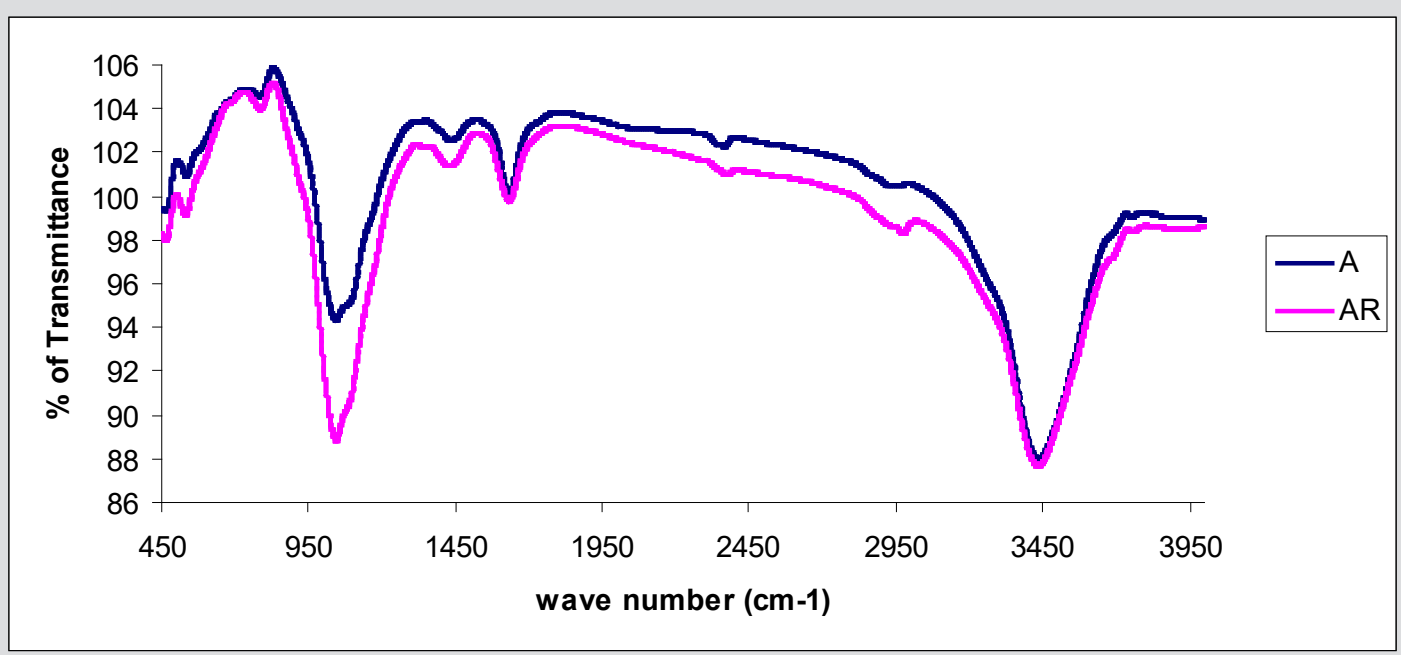

Fig.1. FTIR analysis of alum sludge adsorbent $(A)$ and Rhodamine $B$ dye loaded $A(A R)$

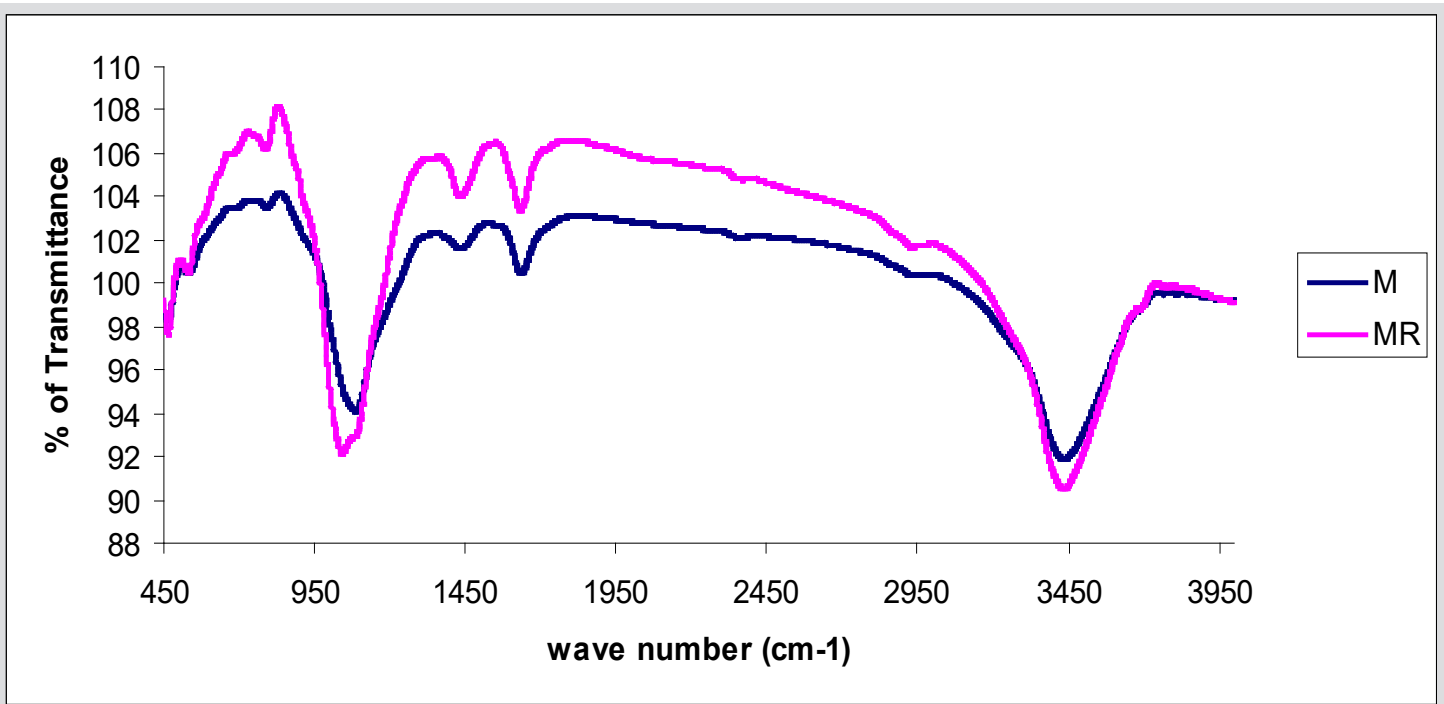

Fig.2. FTIR analysis of mud sludge adsorbent (M) and Rhodamine B dye loaded M (MR)

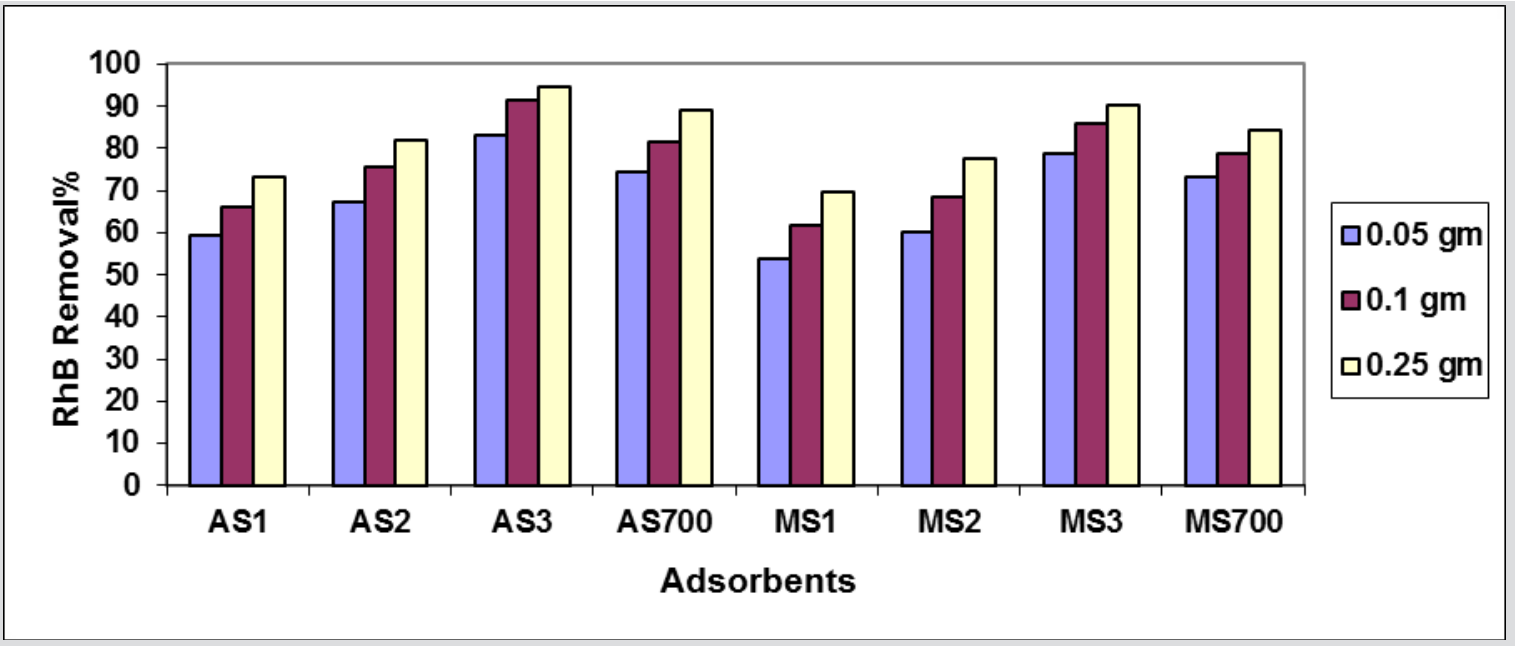

Figure ( 3 ). Effect of Alum and Mud adsorbent dosage on RB dye removal. 
Broadband at $\left(1041 \mathrm{~cm}^{-1}\right.$ and $\left.1085 \mathrm{~cm}^{-1}\right)$ were assigned to the most intense $\mathrm{Si}-\mathrm{O}$ stretching modes.

The peaks at, 785.85-789.707 $\mathrm{cm}^{-1}$ are observed for albite. The observation of the peak in the range $531.29 \mathrm{~cm}^{-1}$ indicates the presence of albite (NaAISi 308; Na- feldspar) mineral absorption band present at $2928.33 \mathrm{~cm}^{-1}$ may suggest the presence of organic carbon These bands are due to $\mathrm{C}-\mathrm{H}$ present in the samples

The presence of quartz in the samples ribbed by the observation of the peaks at 461.86 and $465.72 \mathrm{~cm}^{-1}$ due to Si-O asymmetrical bending vibrations. After RhB dye adsorption, peak shifted to $2972.73 \mathrm{~cm}^{-1}$. While peak at 2364.3 $\mathrm{cm}^{-1}$ characteristic of carbon-and hydrogen containing species with single bond and are assigned to various forms of $\mathrm{C}-\mathrm{H}$ stretching. Also, dye loaded AS shifted to $2372.73 \mathrm{~cm}^{-1}$. The presences of these groups are responsible for adsorption of RhB dye onto the Alum Sludge adsorbent, AS ,surface.The presences of these groups are responsible for adsorption of $\mathrm{RhB}$ dye on to the Mud Sludge adsorbent (MS) .

\subsection{A Comparative Study Between the Developed Adsorbents for RB Removal:}

The chemical activation of alum and mud sludge (Table 2 ) shows that the removal percent of RB by adsorbent activated with acetic acid followed by pyrlosis at $500{ }^{\circ} \mathrm{C}$ was the best at $3 \mathrm{M}$ acetic acid $(72.2 \%)$ for Alum Sludge adsorbent (AS1) and $69.6 \%$ for Mud Sludge adsorbent (MS1) at $0.1 \mathrm{M}$ of acetic acid. Adsorbents of chemicalley activated with acetic acid only revealed the highest removal percent of RB (80.6\%) for Alum Sludge (AS2) at $0.1 \mathrm{M}$ acetic acid , and $77.8 \%$ of Mud Sludge (MS2) at $0.5 \mathrm{M}$ of acetic acid (Table 2 ). The removal efficiency of RB with adsorbent activated with nitric acid (Table 3 ) shows highest efficiency (95.2\% of Alum sludge ,AS3, and $92 \%$ of Mud Sludge,MS3) at $0.25 \mathrm{M}$ nitric acid concentration. In the physical activation of the sludge (Table 4 ) the pyrlosis at $700^{\circ}$ $C$ show the highest removal efficiency of Rh-B (87.8\%) for alum sludge adsorbent (AS700) and $83.7 \%$ of mud sludge adsorbent (MS700). So, the developed adsorbents AS1, AS2, AS3, MS1, MS2, and MS3 were selected as the most chemically activated sludge adsorbents, while AS700 and MS700 adsorbents as the most physically activated sludge adsorbents, and will be used in batch adsorption experiments.

\subsection{Batch Adsorption and Optimization Conditions.}

After selecting the alum sludge adsorbents ( AS1,AS2, AS3, and AS700), and the mud sludge adsorbents (MS1,MS2,MS3, and MS700) as the best chemically and physically adsorbents, the following batch adsorption results of $R B$ dye were discussed to determine the optimum condition for RB dye adsorption .

\subsubsection{Effect of initial RB dye concentration}

The study of the optimum RB dye initial concentration is studied by varying the dye concentration from 50-60-75-100 ppm, while keeping the temperature, adsorbent dose, $\mathrm{pH}$, and contact time constant at $25^{\circ} \mathrm{C}, 0.25 \mathrm{gm}, \mathrm{pH}$ 7 and $90 \mathrm{~min}$, respectively. The effect of initial $\mathrm{RB}$ dye concentration on the removal efficiency by the adsorbents (AS, MS) is indicated in Table ( 5 ). The data evidented that the RB removal percentage decreases with increasing dye concentration, however, the actual amount of the dye is increased.This is due to increase in dye concentration, surface area and active sites of the adsorbent were saturated and hence percentage removal decreases.

Ilayaraja et al. (2013) found that the percentage removal of RB dye using activated carbon decreased from $86.9 \%$ to $52.8 \%$ with an increase in concentration of dye from $20-100 \mathrm{mg} / \mathrm{l}$. Wang et al. (2016) reported that the removal percentage of RB dye on modified zeolities decreased from $93 \%$ to $85 \%$ with the increase of initial dye concentration which the adsorption capacity of RB increased. Akash (2013) found that the percentage of removal of $\mathrm{RB}$ dye on activated Mahua seed carbon (AMC) and activated neem seed carbon (ANC) decreased with the increase of dye concentration (50-100150) ppm from $92 \%$ to $83 \%$ to AMC and from $82 \%$ to $64 \%$ to ANC.

\subsubsection{Effect of adsorbent dosage}

In these experiments, target RB dye solutions with a concentration of 50 ppm were placed in contact with various amounts of adsorbent $(0.05$, 0.1 and $0.25 \mathrm{~cm})$, keeping other parameter $(\mathrm{pH}$, 


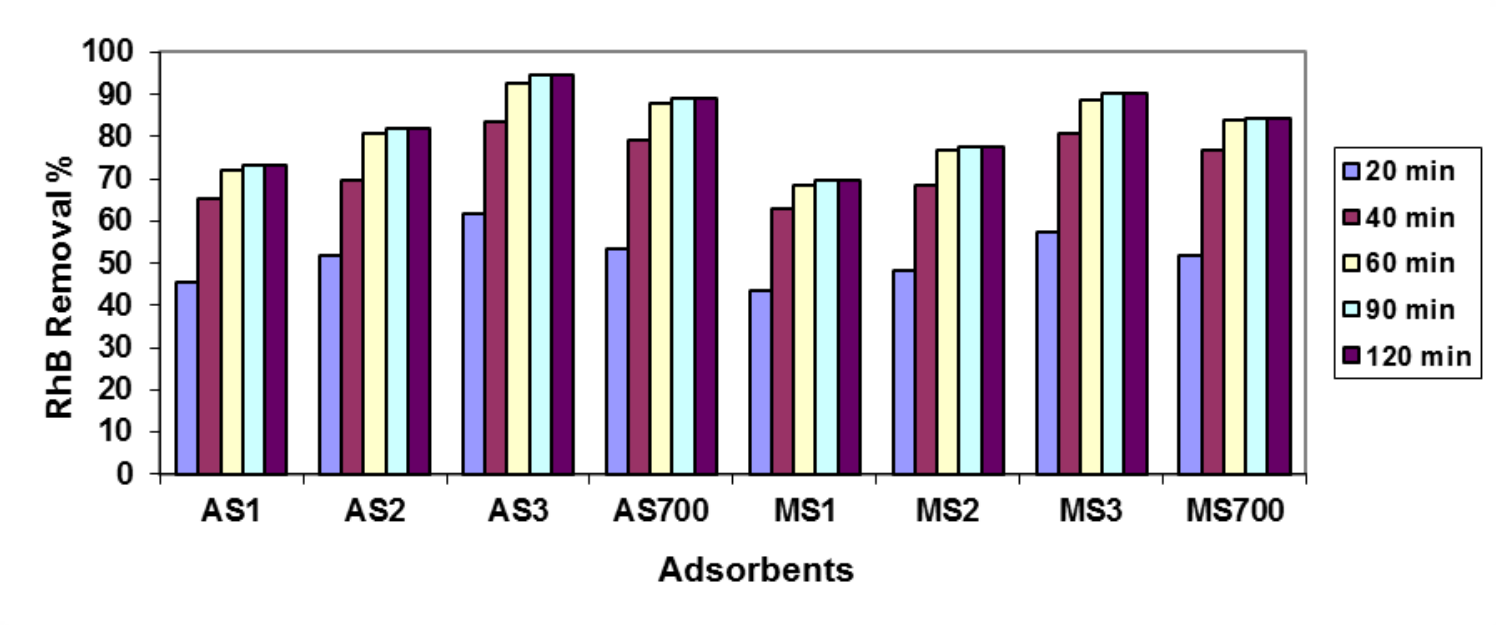

Figure ( 4 ). Effect of Alum and Mud adsorbent contact time on RB dye removal.

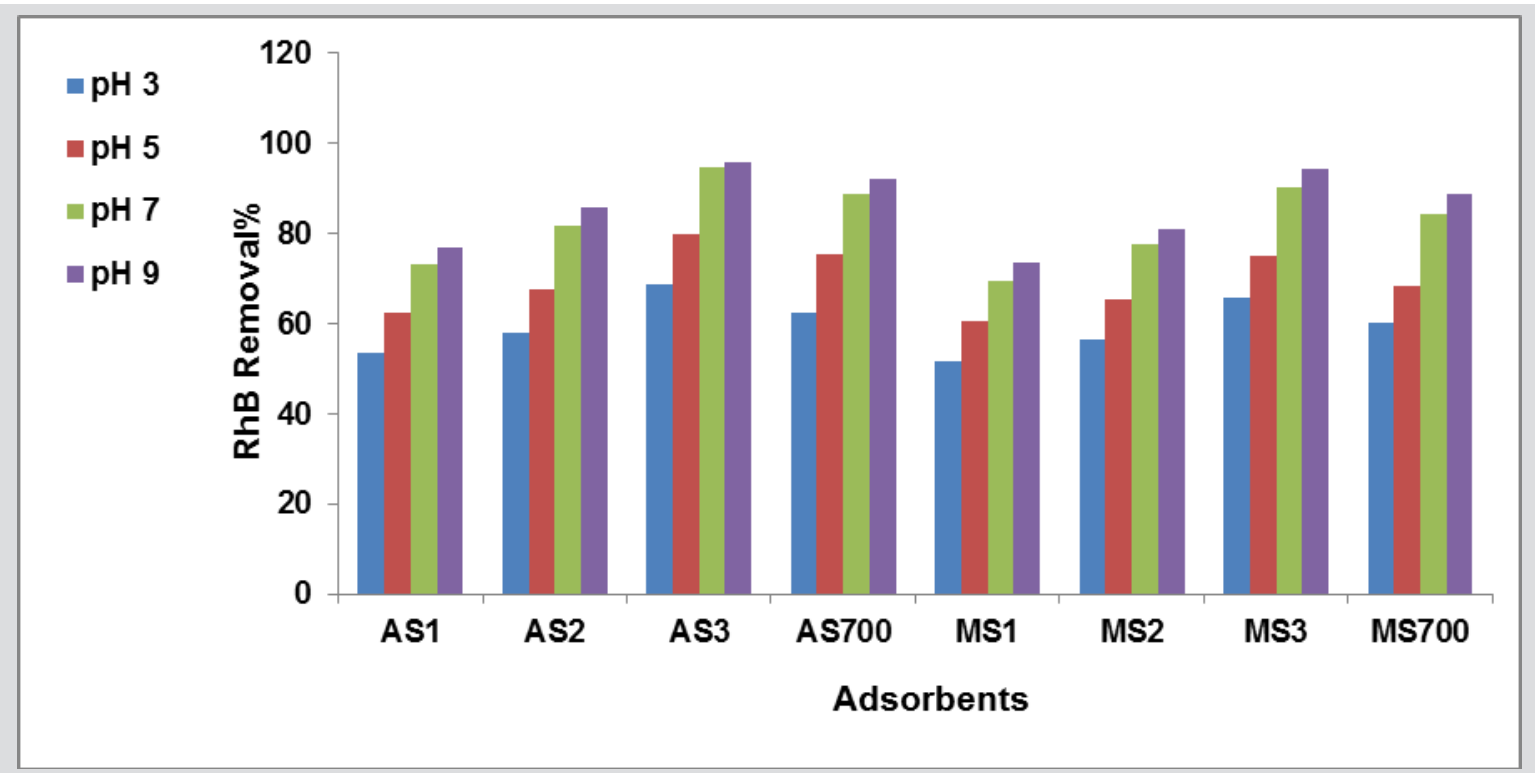

Figure ( 5 ). Effect of Alum and Mud adsorbent $\mathrm{pH}$ on RB dye removal.

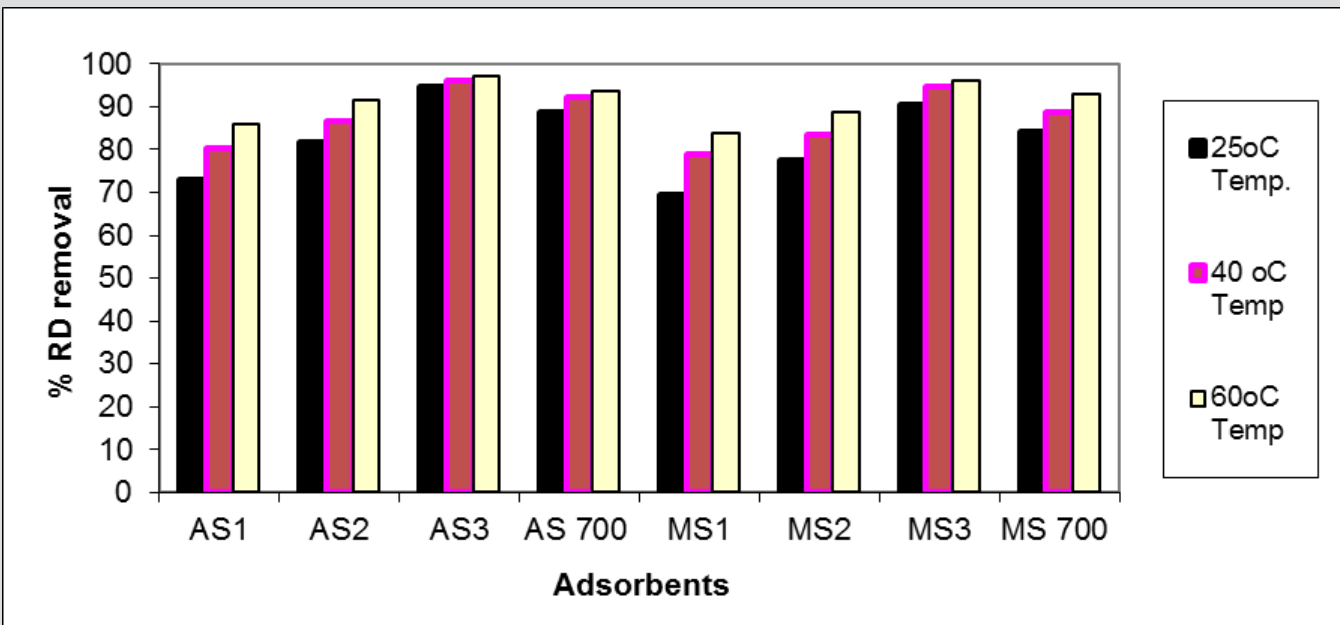

Figure ( 6 ). Effect of Alum and Mud adsorbent temperature on RB dye removal. 
contact time and temp.) constant. The results are presented in Fig (3) which show that the removal percentage of RB dye increase with increasing adsorbent dose (Alum and Mud) and reached high removal efficiencies with $0.25 \mathrm{gm}$ adsorbent; this because of the number of available adsorption site increases by an increase in adsorbent dose.

Danitel and Shoba ( 2015), they found that the removal percentage of RD dye adsorbed increase along with the increase of adsorbent dosage of carbon from 50 to $150 \mathrm{mg} / \mathrm{l}$. Ilayaraja et al ( 2013) found that the removal percentage of RB dye increased with increasing the MAC sorbent dose (maranta arundinacea activated carbon) due to the availability of higher number of adsorbing active sites. This increase was from 88.6 to $92.1 \%$ with increase dose from 0.2 to 1.0 $\mathrm{gm}$. A similar result was reported for adsorption of RB on magnesium oxide.

Wang-Yu et al (2016) reported that the removal percentage of Rhodamine $B$ using modified zeolites increased, when the volume and concentration of the solution were fixed, with the increase of the dosage of the modified zeolites. The free active sites which were employed on the adsorbent increased and the unit adsorbing capacity of Rhodamime B in the solution using modified zeolites decreased. Amina et al.( 2015) reported that with increase activated carbon prepared from the sewage sludge dose to $5 \mathrm{gm}$ , induces RB dye removal higher than $90 \%$. Daniela et al. (2008) found that the percent of the RD dye removal increase with the increasing of the sawdust doses, due to the higher number of available sorption sites. Balasubramani and Sivara ( 2014) concluded that the percentage of RB dye sorbed increased as the sorbent dose was increased over the rang 1-3 gm. The adsorption of the RB dye increased from 60 to 70 $\%$ with the increase in sorbent dose. This is due to the increase in dosage increase the availability of active sites to the dye molecules.

\subsubsection{Effect of contact time on RB dye adsorption}

In order to determine the optimum contact time for RB dye removal, its value was varied in the range of (20-40-60-90-120 min) in a series of experiments in which the initial dye concentration, the temperature, $\mathrm{pH}$ and adsorbent dose were kept constant at $50 \mathrm{ppm}, 25^{\circ} \mathrm{C}, \mathrm{pH} 7$ and $0.25 \mathrm{gm}$ respectively. The effect of contact time on RB dye removal of by Alum and Mud sludge adsorbents are indicated in Fig. (4).

The results from Fig. (4) showed that the removal percentage of $\mathrm{RB}$ dye with Alum and Mud adsorbents increased with increasing contact time from 20 to 90 min after that it remain constant up to120 $\mathrm{min}$. So that the $90 \mathrm{~min}$ as contact time was enough to achieve maximum adsorption of RB on the surface of Alum and Mud adsorbents.

The removal percentage of $\mathrm{RB}$ on $\mathrm{AS} 1, \mathrm{AS} 2$, AS3 and AS4 adsorbents increase from 45.5\% to $73.09,51.68 \%$ to $81.78 \%, 61.79 \%$ to $94.57 \%$ and $53.3 \%$ to $88.91 \%$, respectively as contact time increased from 20 to $90 \mathrm{~min}$. While the removal of RB by MS1, MS2, MS3 and MS4 adsorbents increase from $43,36 \%$ to 69.55 , $48.27 \%$ to $77.58,57.23 \%$ to $90.45 \%$ and 51.77 to $84.23 \%$, respectively as contact time increased from 20 to $90 \mathrm{~min}$. The qt was increased with the increase of time for all samples up to $90 \mathrm{~min}$, this explained that nearly after 90 minutes qe equilibrium reached and $\mathrm{RB}$ dye removal also become constant. So the optimal contact time for RB dye adsorption on the developed adsorbents was 90 minute. This optimal time period was the sufficient time for stabilization of this adsorbent and adsorbate dispersed solution.

Balasubramani and Sivarajaskar (2014) found that the percentage of removal of RB dye increase with increase time the equilibrium time was 3 hours for adsorption RB dye on activated carbon (coconut shell activated carbon). Akash and Arvind (2013) reported that nearly after 180 minutes the qe equilibrium reached and percentage removal of RB dye on AMC(activated Mahua seed carbon) also become constant, so that the optimal contact time of adsorbent the RB dye on AMC was 180 min. This time was the sufficient time for stabilization of this adsorbent. Ilayaraja et al. (2013) studied the equilibrium time for the adsorption of RB dye on MAC (Maranta arundinacea activated carbon) from 20 to 140 min. The optimum time removal was found to be $40 \mathrm{~min}$. The removal percentage of RB dye increased from $88.6 \%$ to $91.3 \%$ from 20 to $40 \mathrm{~min}$ then remain constant. Daniel and Shoba ( 2015) observed that the uptake of the RB dye increases with time, and the extent of adsorption is rapid in 
the initial stage and become slow in later stage till saturation is attained around 2 hours. This shows that equilibrium can be assumed to be achieved by 2 hours of contact time

\subsubsection{Effect of $\mathrm{pH}$}

The $\mathrm{pH}$ of the dye solution plays an important role in the whole adsorption process. The effect of solution $\mathrm{pH}$ of the RB dye adsorption on Alum and Mud sludge adsorbents were determined at $\mathrm{pH}(3,5,7$ and 9$)$ with a fixed adsorbent dose of $0.25 \mathrm{mg} / 100 \mathrm{ml} \mathrm{RB}$ dye concentration $50 \mathrm{ppm}$ at $25^{\circ} \mathrm{C}$ and contact time $90 \mathrm{~min}$. The solution $\mathrm{pH}$ was controlled by the addition of $0.1 \mathrm{M} \mathrm{HCl}$ or 0.1 $\mathrm{NaOH}$. The results showed in Fig. (5) pointed out that the removal percentage of RB increased with increasing $\mathrm{pH}$ from 3 to 9 . In case of alum sludge adsorbent, removal percentage increased for AS1 (from 53.6 to $76.8 \%$ ) , AS2(from 58 to $86 \%$ ) , AS3 (from 68.7 to $96 \%$ ) and AS4 (from 62.5 to $91.98 \%$ ) , while with Mud sludge adsorbent RB dye removal were increased for MS1 (from51.6 to $73.5 \%$ ), MS2 (from 56.4 to $80.89 \%$ ), MS3 ( from 65.7 to $94.5 \%$ ), and MS4 (from 60.33 to88.7\%).At that solution $\mathrm{pH}$ the adsorbent surface negatively charged and favors uptake of cationic dyes due to increased electrostatic force of attraction.

A similar result was reported by Balasubr and Sivarajasekar (2014) who found that the removal percentage of RB dye on coconut shell activated carbon increased with increased $\mathrm{pH}$ from 2 to 9 . They studied the effect of $\mathrm{pH}$ on RB dye adsorption on the activated carbon and found that the dye removal was maximum at acidic condition $(<7)$. The reason for this behavior is due to that the RB molecules are positively charged, and as the initial $\mathrm{pH}$ of the test solution increased, the number of negatively charged adsorbent sites increased and positively charged adsorbent sites decreased, which favors the adsorption of positively charged dye cation due to electrostatic attraction. Thus at higher $\mathrm{pH}$ adsorption will be more and lower $\mathrm{pH}$ adsorption will be lesser . Nity et al. ( 2008) found that the effect of $\mathrm{pH}$ on the percentage removal of the RB dye by activated carbon increased with increasing $\mathrm{pH}$ from 3 to 7 , and above $\mathrm{pH} 7.5$ removal of $\mathrm{RB}$ decrease with increase in $\mathrm{pH}$. Gurusamy et al.( 2002) studied the effect of solution $\mathrm{pH}$ on the adsorption of dyes (MO,MB,RB,CR,MV and AV
) by banana and orange peels found that the amount of adsorption increases when the $\mathrm{pH}$ is increased. The adsorption capacities reach maximum at $\mathrm{pH} \mathrm{6-7} \mathrm{but} \mathrm{decreased} \mathrm{when} \mathrm{pH}$ is increased further .

\subsubsection{Effect of temperature}

The effect of temperature on the adsorption of RB on Alum and Mud sludge adsorbents has been studied with different solution temperature $\left(25^{\circ} \mathrm{C}, 40^{\circ} \mathrm{C}, 60^{\circ} \mathrm{C}\right)$. The experiment was performed at adsorbent dose $0.25 \mathrm{gm}$, target dye concentration $50 \mathrm{ppm}$, contact time $90 \mathrm{~min}$ and $\mathrm{pH}$ 7. The results are represented in Fig. (6), It showed that the removal percentage of RB dye on Alum and Mud sludge increased with increasing the temperature from $25^{\circ} \mathrm{C}$ to $60^{\circ} \mathrm{C}$. The equilibrium of RB adsorption capacity of both adsorbents (AS and MS) were better at higher temperatures as the adsorbed amount of $R B$ increases with the rise in temperature. Higher RB uptake at high temperature is due to the increase in molecular diffusion or may be attributed to the availability of more active sites on surface area. This result indicated that the adsorption of RB dye was an endothermic process.

Similar results have been reported for the adsorption of RB dye by Ilayaraja, et al.( 2013) and showed that the adsorption of both CR and RB on MAC is favored by an increase in temperature. Akash and Arvind (2013) reported that the adsorption capacity of RB dye on AMC increases with increase temperature from 35 ${ }^{\circ} \mathrm{C}$ to $65^{\circ} \mathrm{C}$. Daniela et al.( 2008) found that the removal percentage of all dyes (MB, CV, RB and $B$ red) on sawdust are greater at increase the temperature the sorption process is an endothermic.

\subsection{Adsorption Isotherms}

The experimental data collected at $25^{\circ} \mathrm{C}$, initial dye concentration $50 \mathrm{ppm}, 0.25 \mathrm{gm}$ of sludge adsorbent, and $90 \mathrm{~min}$. The data were fitted into the following isotherms: Langmuir, Freundlich, Temkine and Dubinin-Raduskevich (D-R) isotherm models.

\subsubsection{Langmuir isotherm:}

The Langmuir model assumes that the solid surface carries a limited number of sites that are 
characterized by equal energy of adsorption, independent of the degree of coverage and thus indicating a monolayer adsorption. The linearized form of Langmuir equation is described by equation:

$$
\mathrm{Ce} / \mathrm{qe}=1 / \mathrm{Qobl}+\mathrm{Ce} / \mathrm{Qo}
$$

Where $\mathrm{Ce}$ is the equilibrium concentration of dye solution $(\mathrm{mg} / \mathrm{l})$, qe the equilibrium capacity of dye on adsorbent $(\mathrm{mg} / \mathrm{g})$, Qo is monolayer adsorption capacity of adsorbent $(\mathrm{mg} / \mathrm{g})$ and $\mathrm{bl}$ is the Langmuir bonding energy coefficient $(\mathrm{L} / \mathrm{mg})$.

The bl and Qo can be calculated from the intercept and slope of the linear plot of $\mathrm{Ce} / q \mathrm{q}$ against $\mathrm{Ce}$.

From data in Table ( 6 ), $R^{2}=0.99$ and bl values lies between 0 to 1 and indicating the favorable sorption of RB dye on both Alum and Mud sludge adsorbents. Therefore, monolayer coverage of RB on Alum and Mud sludge adsorbent particles is assumed with the maximum adsorption capacity of $23.36 \mathrm{mg} / \mathrm{g}$ for AS1,24.09 mg/g for AS2 , $25.64 \mathrm{mg} / \mathrm{g}$ for AS3 ,and $24.69 \mathrm{mg} / \mathrm{g}$ for AS4 for Alum sludge adsorbent, while for Mud sludge adsorbent it were $22.72 \mathrm{mg} / \mathrm{g}$ for MS1

$23.69 \mathrm{mg} / \mathrm{g}$ for MS2, $25.70 \mathrm{mg} / \mathrm{g}$ for MS3 and $27.55 \mathrm{mg} / \mathrm{g}$ for MS4.The RB sorption data on both AS and MS adsorbents fitted well to langmuir isotherm model.

\subsubsection{Freundlich isotherm:}

The Freundlich equation is used to determine the applicability of heterogeneous surface energy in the adsorption process. The empirical Freundlich equation is expressed as:

$$
\log q e=\log K f+1 / n \log C e
$$

Where $\mathrm{Kf}$ is the Freundlich isotherm constants indicating the adsorption capacity, and $\mathrm{n}$ is the adsorption intensity. If the $1 / n$ values are below one it indicates a normal adsorption, on the other hand $1 / \mathrm{n}$ being above one indicates cooperation adsorption. The $\mathrm{Kf}$ and $\mathrm{n}$ can be calculated from the intercept and slope of the linear plot of $\log$ qe against $\log \mathrm{Ce}$. The values of $\mathrm{Kf}$ and $1 / \mathrm{n}$ given in the Table 6 which indicate an effective adsorption. It also indicates the degree of adsorption favorability of. Higher values of $\mathrm{kf}$ indicate higher affinity for RB adsorption.
From the results of Langmiur and Freundlish data it was clearly observed that both models were well suited for adsorption of RB dye on AS and MS adsorbents, but the regression factor as well as the calculated and experimental values correlated more correctly with the langmuir values, on this basis it could be concluded that RB form monolayer on surface of sludge.

\subsubsection{The Temkin Isotherm:}

The Temkin isotherm model predicts a uniform distribution of binding energies over the population of surface binding adsorption. Linear form of Temkin equation is expressed as:

$$
\mathrm{qe}=\mathrm{B} \ln \mathrm{K}+\mathrm{B} \ln \mathrm{Ce}
$$

Where $B$ is $R T / b$, and $b$ is the Temkin constant related to heat of sorption . qe $(\mathrm{mg} / \mathrm{g})$ and $\mathrm{Ce}$ $(\mathrm{mg} / \mathrm{l})$ are the amount of adsorbed dye per unite weight of adsorbent and unabsorbed dye concentration in solution at equilibrium, respectively. Therefore, a plot of qe versus $\ln \mathrm{Ce}$ enables one to determine the constant $B$ that is the constant related to the heat of sorption $(\mathrm{J} /$ $\mathrm{mol})$, and $\mathrm{K}$ is the equilibrium binding constant (Table 6).

\subsubsection{Dubinin- Radushkevich isotherm model:}

Dubinin- Radushkevich isotherm is applied to express the adsorption mechanism with a Gaussian energy distribution onto a heterogeneous surface ( Gunay and Arslankaya,2007 ; Dabrowski,2001). It means that it is applied to distinguish between physical and chemical adsorption of dye.

The linearized D-R equation (Chen, et.al, 2008) may be written as:

$$
\operatorname{Ln} q e=\ln q m-B E^{2}
$$

Where $B$ aconstant related to the adsorption energy $\left(\mathrm{mol}^{2} / \mathrm{kJ}^{2}\right)$, qm is a constant that indicates the sorption degree characterizing the sorbent $(\mathrm{mg} / \mathrm{g})$, and $\mathrm{E}$ is the polany potential, which can be obtained by following equation:

$$
E=R T \ln (1+1 / \mathrm{Ce})
$$

Where $R$ is the ideal gas constant $(R=8.314 \mathrm{~J} /$ $\mathrm{mol} \mathrm{K}$ ) and $\mathrm{T}$ is the absolute temperature (K). By plotting In qe vs $E^{2}$, it is possible to determine 
Rashed et al., AJSRE, 2016; Vol. 1(1): 0013-0030

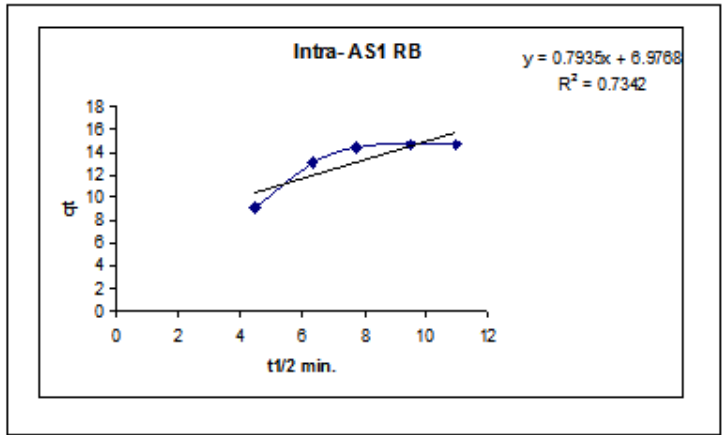

(A) AS1

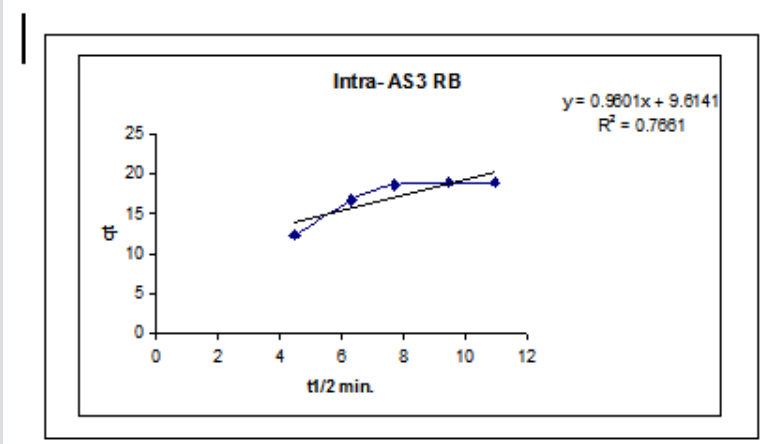

(C) AS3

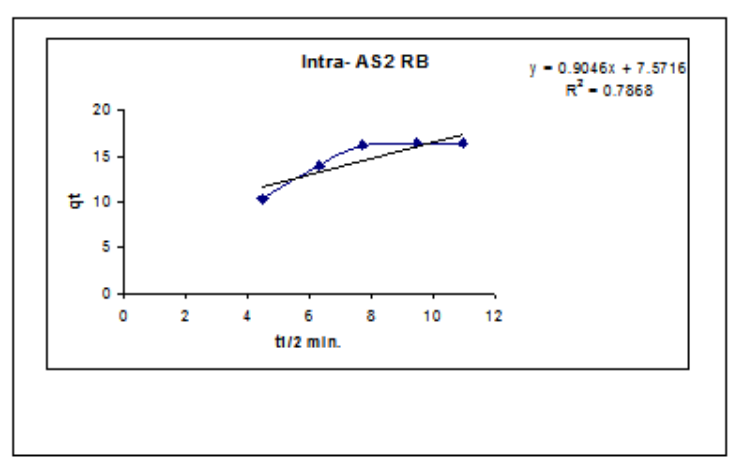

(B) AS2

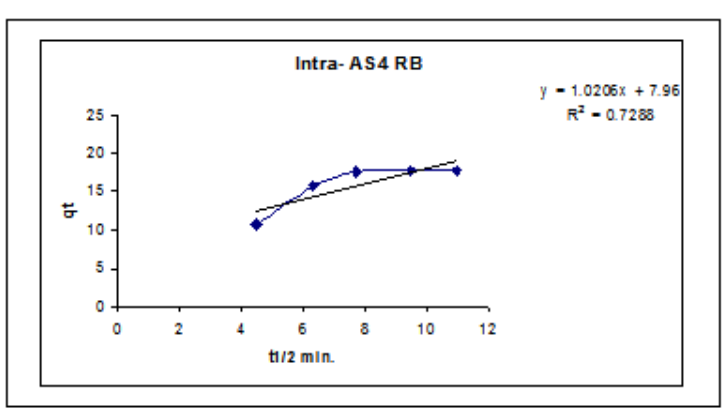

(D)AS700

Figure ( 7 ). The intra-particle kinetic for the adsorption of RB by AS adsorbents.

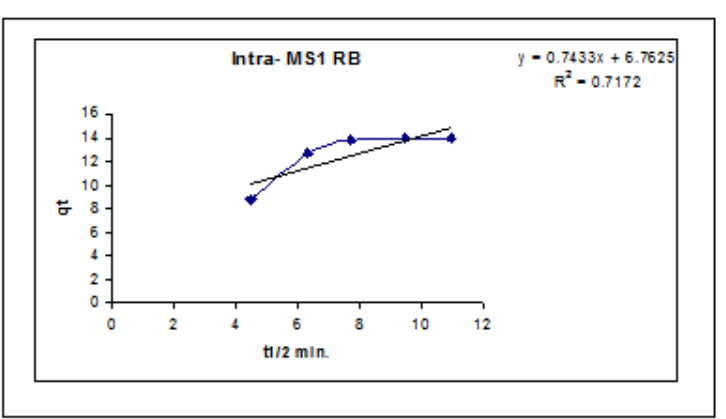

(A) MS1

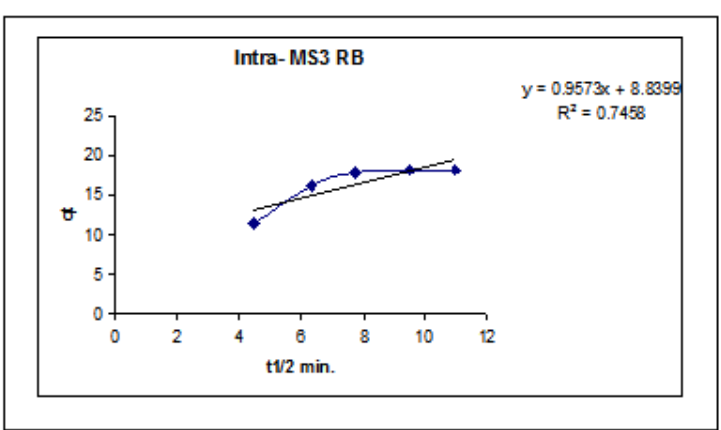

(C) MS3

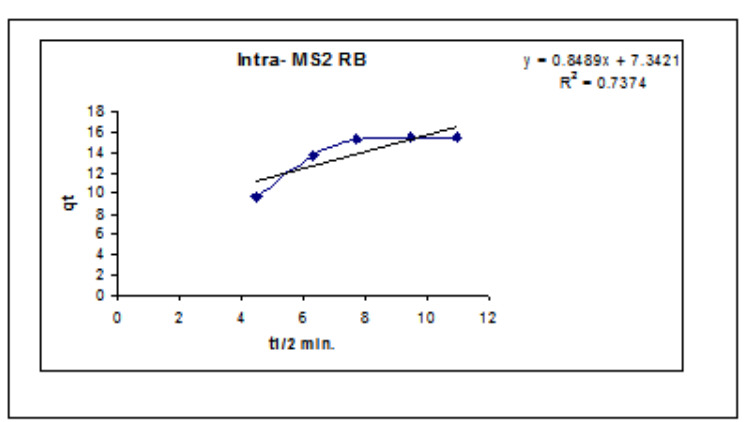

(B) MS2

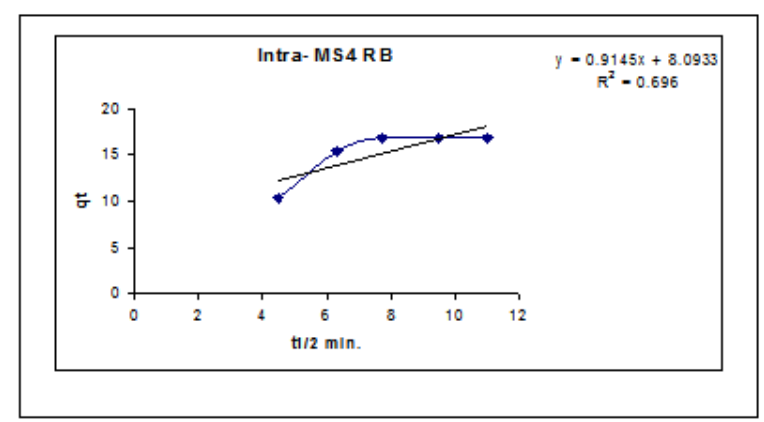

(D) MS700

Figure ( 8 ). The intra-particle kinetic for the adsorption of RB by MS adsorbents. 
the value of $B$ from the slope and the value of $q m$ from the intercept, which is In qm. The mean free energy $E(\mathrm{KJ} / \mathrm{mol})$ of sorption can be estimated by using $B$ values as expressed in the following equation (Chowdhury and Saha, 2010).

$$
E=1 /(2 B)^{1 / 2}
$$

The magnitude of $E$ may characterize the type of the adsorption as chemical ion exchange $(E=8-$ $16 \mathrm{~kJ} / \mathrm{mol})$, or physical adsorption $(\mathrm{E}<8 \mathrm{~kJ} / \mathrm{mol})$ (Sivakumar and Rupainwar 2011). From Table (6) it can be observed that the obtained values of the mean free energy are limited within the range of 0.224 to $1.291 \mathrm{~kg} / \mathrm{mol}$. Based on these data, it can thus be concluded that the effect of physical adsorption will play a dominating role in the adsorption process of RB dye adsorption onto the adsorbents. The similar result was reported for adsorption of RB and CR on MAC by llayaraja et al. (2013) whom found that the adsorption of RB and $\mathrm{CR}$ dyes physical adsorption process. The sorption data fitted into Langmuir, Freundlich, Temkin and Dubunin - Radushkevich isotherms out of which Langmuir Adsorption model was found to have the highest regression value and hence the best fit.

\subsection{Adsorption Kinetic Studies:}

Kinetic models have been proposed to determine the mechanism of the adsorption process which provides useful data to improve the efficiency of the adsorption and feasibility of process scale-up (Eftekhari et al . 2010). It means to describe the rate of uptake of dyes onto the adsorbents and this rate controls the equilibrium time.

The kinetics adsorption that define the efficiency of RB dye adsorption on Alum and Mud sludge adsorbents were checked by the Pseudo - first order, Pseudo - second order , Intra - particle diffusion and Elovich models. These models include all steps of adsorption which include external film diffusion, internal particle diffusion and adsorption.

\subsubsection{Pseudo - first order model}

The pseudo- first order kinetic model is represented as follows:

$$
\log (q e-q t)=\log q e-(k 1 / 2.303) t
$$

Where, qe and qt $(\mathrm{mg} / \mathrm{g})$ are the sorption capacities at equilibrium and time (min) respectively, and $\mathrm{k} 1$ is the rate constant of the pseudo- first order (Kamal et al.,2010) ; Inbaraj and Sulochana,2005).

A plot of log (qe-qt) vs $t$ should give linear relationship with the slop k1and intercept of log qe the data showed in Table 7.The kinetic parameters and the correlation coefficients for adsorption of RB dye on Alum and Mud sludge adsorbents are presented in Table 7 .

\subsubsection{Pseudo - second order model:}

The linearized form of the pseudo - second order kinetic model is represented as:

$$
t / q t=1 / k 2 q e^{2}+1 / q e t
$$

Where $\mathrm{k} 2$ is the rate constant of pseudo - second order adsorption ( $\mathrm{g} / \mathrm{mg} / \mathrm{min})$.

A plot of $t / q t$ vs $t$ shows a linear relationship values of $\mathrm{k}_{2}$ and equilibrium adsorption capacity qe were calculated from intercept and slop of the plot. The data in Table( 7 ) shown that the correlation co-efficient $\left(R^{2}\right)$ is high for pseudo second order. So that the adsorption of RhB dye by Alum and Mud sludge adsorbents are to follow the pseudo second order kinetic.

\subsubsection{Intra-particle diffusion model:}

For solid - liquid adsorption process, the solute transfer is usually characterized by intra particle diffusion model proposed by Weber and Morris (1963) which was used to identify the mechanism involved in the adsorption process:

$$
q t=k_{i} t \frac{1}{2}+C
$$

Where, $\mathrm{k}_{\mathrm{i}}\left(\mathrm{mg} \mathrm{g}^{-1} \mathrm{~min}^{-1 / 2}\right)$ is the rate constant of the intra-particle diffusion model and $\mathrm{C}\left(\mathrm{mg} \mathrm{g}^{-1}\right)$ is intraparticle diffusion constant i.e. intercept of the line $\left(\mathrm{mgg}^{-1}\right)$. It is directly proportional to the boundary layer thickness, and reflects the boundary layer effect. The $\mathrm{k}_{\mathrm{i}}$ and $\mathrm{C}$ can be determined from the slop and intercept of the linear plot of qt vs $t^{1 / 2}$ Figs. (7\&8).

The experimental data were used for intraparticle diffusion model( intraparticle diffusion constant $\left[K_{i d}\right]$, intercept and the correlation co-efficient [ $\left.R^{2}\right]$ ) are calculated. 
Rashed et al., AJSRE, 2016; Vol. 1(1): 0013-0030

Table 7. Calculated kinetic parameters for the adsorption of Rhodamine B dye onto Alum and Mud sludge adsorbents.

\begin{tabular}{|c|c|c|c|c|c|c|c|c|}
\hline Parameters & AS1 & AS2 & AS3 & AS4 & MS1 & MS2 & MS3 & MS4 \\
\hline \multicolumn{9}{|c|}{ Pseudo first order } \\
\hline $\mathrm{K}_{1}(\min )^{-1}$ & 0.0859 & 0.08153 & 0.0732 & 0.0859 & 0.0804 & 0.0953 & 0.0726 & 0.1048 \\
\hline qe $(\mathrm{mg} / \mathrm{g})$ & 36.058 & 39.03 & 31.989 & 45.783 & 28.249 & 50.119 & 30.4019 & 65.494 \\
\hline $\mathrm{R}^{2}$ & 0.9752 & 0.9401 & 0.9803 & 0.9789 & 0.9934 & 0.955 & 0.993 & 0.9695 \\
\hline \multicolumn{9}{|c|}{ Pseudo second order } \\
\hline $\begin{array}{c}\mathrm{K}_{2}(\mathrm{~g} / \mathrm{mg} \\
\mathrm{min})\end{array}$ & $5.071^{*} 10^{-3}$ & $4.215^{*} 10^{-3}$ & $4.303 * 10^{-3}$ & $3.755^{*} 10^{-3}$ & $5.514 * 10^{-3}$ & $\begin{array}{c}4.716 * 10 \\
3\end{array}$ & $4.2348 * 10^{-3}$ & $4.5095 * 10^{-3}$ \\
\hline qe $(\mathrm{mg} / \mathrm{g})$ & 16.393 & 18.45 & 21.0084 & 20.161 & 15.552 & 17.422 & 20.2020 & 18.868 \\
\hline $\mathrm{R}^{2}$ & 0.9934 & 0.9947 & 0.996 & 0.9916 & 0.9933 & 0.9932 & 0.9947 & 0.9916 \\
\hline \multicolumn{9}{|c|}{ Elovich model } \\
\hline$\alpha(\mathrm{mg} / \mathrm{min})$ & 3.996 & 4.235 & 6.7692 & 3.967 & 4.0096 & 4.1297 & 5.4429 & 4.5693 \\
\hline$\beta$ (g/mg) & 0.3247 & 0.288 & 0.26996 & 0.2522 & 0.3455 & 0.3037 & 0.2697 & 0.2797 \\
\hline $\mathrm{R}^{2}$ & 0.8422 & 0.8826 & 0.8683 & 0.8378 & 0.8278 & 0.8448 & 0.8519 & 0.8097 \\
\hline \multicolumn{9}{|c|}{ Intra particle diffusion model } \\
\hline $\mathrm{K}_{\mathrm{id}}$ & 0.7935 & 0.9046 & 0.9601 & 1.0206 & 0.7433 & 0.8489 & 0.9573 & 0.9145 \\
\hline $\mathrm{C}(\mathrm{mg} / \mathrm{g})$ & 6.9768 & 7.5716 & 9.6141 & 7.96 & 6.7625 & 7.3421 & 8.8399 & 8.0933 \\
\hline $\mathrm{R}^{2}$ & 0.7342 & 0.7868 & 0.7661 & 0.7288 & 0.7172 & 0.7374 & 0.7458 & 0.696 \\
\hline
\end{tabular}

Table 8. Thermodynamical parameters for the adsorption of Rhodamine B dye onto Alum and Mud Sludge adsorbents.

\begin{tabular}{|c|c|c|c|c|c|c|c|c|c|}
\hline \multicolumn{2}{|c|}{ Parameters } & AS1 & As2 & As3 & As4 & MS1 & MS2 & MS3 & MS4 \\
\hline \multicolumn{2}{|c|}{$\Delta \mathrm{H}^{0}, \mathrm{~kJ} / \mathrm{mol}$} & 19.2178 & 21.1783 & 15.773 & 14.1446 & 18.9983 & 19.1139 & 15.2296 & 20.9621 \\
\hline \multicolumn{2}{|c|}{$\Delta \mathrm{S}^{0}, \mathrm{~kJ} / \mathrm{K} / \mathrm{mol}$} & 0.06531 & 0.07583 & 0.06928 & 0.05769 & 0.06339 & 0.06687 & 0.06223 & 0.07657 \\
\hline \multirow[b]{3}{*}{$\begin{array}{c}\Delta \mathrm{G}^{0}, \mathrm{~kJ} / \\
\mathrm{mol}\end{array}$} & $298 k$ & -0.2438 & -1.4189 & -4.8729 & -3.0463 & -0.1081 & -0.8132 & -3.3163 & -1.8571 \\
\hline & $313 k$ & -1.2242 & -2.5565 & -5.9121 & -3.9124 & -0.8428 & -1.8163 & -4.2498 & -3.0057 \\
\hline & $333 k$ & -2.5304 & -4.0731 & -7.2977 & -5.0662 & -2.111 & -3.1536 & -5.4945 & -4.5372 \\
\hline \multicolumn{2}{|c|}{$R^{2}$} & 0.9968 & 0.9979 & 0.9869 & 0.9701 & 0.9666 & 0.9999 & 0.9991 & 0.9987 \\
\hline
\end{tabular}


The intraparticle diffusion plots of 'qt' vs 't ${ }^{1 / 2}$ ' for the adsorption of Rh.B dye on AS and MS adsorbents are shown from in Figures (7\&8) and the values are given in Table 7 . From the figures (7 \&8), the first line would represent fast uptake and rapid transfer of adsorbate Rh.B dye onto the adsorbent surface by physical/chemical forces. The line in the initial stage does not pass through the origin this makes it noteworthy that uptake is dominated by film diffusion than it does for the intraparticle diffusion process. . In the second stage, , sorbate adsorption speeds up reflecting non consecutive diffusion of sorbate molecules into the micropores with pore width within the sorbent, while the third stage shows saturation of adsorbent surface. High regression coefficient values obtained also indicated a possible role of diffusion within particles during Rh.B sorption. Generally, adsorption controlled by the intraparticle model is due to the preferential adsorption of sorbate in the micropores (Biyan et al., 2009).

From these data the intercept value indicates that the lines are not passing through origin, therefore some other process that may affect the adsorption. The correlation coefficient $\left[\mathrm{R}^{2}\right]$ value is less than that of pseudo second order model.

\subsubsection{Elovich model:}

One of the most useful models for describing such adsorption kinetic of activated chemisorptions is Elovich equation.

The Elovich equation was: $\quad q t=1 / \beta \ln [\alpha \beta]+1 / \beta$ Int

Where, $\alpha$, the initial adsorption and $\beta$, the desorption coefficient

The constant $\alpha$ and $\beta$ are calculated from plots obtained when qe is plotted vs In $\mathrm{t}$.

The results are shown in Table (7). The parameters of Elovich kinetic model $\alpha, \beta$ and correlation coefficient $\left[\mathrm{R}^{2}\right]$ are summarized in Table (7).

The data obtained from Elovich model ( the initial adsorption rate $[\alpha]$, desorption constant $[\beta]$ and the correlation co-efficient $\left(R^{2}\right)$ were calculated and tabulated in Table ( 7 ). The correlation coefficient $\left[R^{2}\right]$ is less than that of pseudo second order model.The desorption coefficient $(\beta)$, which is related to surface coverage, increases with an increase in the initial dye concentration indicating the decrease in availability of adsorption surface for the adsorbate. The constant $(\alpha)$ is an indication of the number of sites available for the adsorption. The correlation coefficient value $\left(R^{2}\right)$ is found to be linear indicating favorable

adsorption but the value is less when compared to pseudo second order kinetic model.

Finally from Table (7) it indicates that all these four kinetic models, applied for adsorption of RhB on Alum and Mud sludge adsorpents, are to follow pseudo second order kinetic model.

\subsection{Thermodynamics of adsorption:}

The thermodynamic parameters such as changes in Gibbs free energy $\left(\Delta \mathrm{G}^{0}\right)$, enthalpy $\left(\Delta \mathrm{H}^{0}\right)$ and entropy $\left(\Delta S^{0}\right)$ are the actual indicators for particle applications. Adsorption thermodynamics were evaluated with respect to different temperatures $(298,313$, and $333 \mathrm{~K})$

The thermodynamic parameters were calculated by the following equation:

$$
\text { Ln } k=\Delta S^{0} / R-\Delta H^{0} / R T
$$

Where, $\mathrm{R}$ is the gas constant $(8.314 \mathrm{~J} / \mathrm{mol} \mathrm{K}$ ) and $\mathrm{T}$ is temperature $(\mathrm{K})$.

Both $\Delta \mathrm{H}^{0}$ and $\Delta \mathrm{S}^{0}$ were determined from the slope and intercept of the van'tHoff plots of In $\mathrm{k}$ vs 1/T (Ozcan et al., 2006, Nollet et al., 2003) The free energy of specific adsorption $\Delta \mathrm{G}^{0}(\mathrm{KJ} /$ $\mathrm{mol}$ ) is calculated from the following expression.

$$
\Delta \mathrm{G}^{0}=\Delta \mathrm{H}^{0}-\mathrm{T} \Delta \mathrm{S}^{0}
$$

The estimated thermodynamic parameters are presented in Table (8). The adsorption data indicate that $\Delta G^{\circ}$ values were negative at all temperatures. That negative $\Delta \mathrm{G}^{\circ}$ confirms the spontaneous nature of adsorption of RhB by alum and mud sludge adsorbents. The parameter $\Delta G^{\circ}$ suggests that adsorption of $\mathrm{RhB}$ is physical adsorption process. The positive values of $\Delta \mathrm{H}^{\circ}$ were further confirmed the endothermic nature of adsorption process. The positive $\Delta S^{\circ}$ showed increased randomness at the solid - solution interface during the adsorption of RhB by Alum and Mud sludge adsorbents. 


\section{Conclusion}

The present study shows that Alum and Mud sludge adsorbents are an effective adsorbent for the removal of RhB dye from aqueous solution. The adsorption followed the Langmuir isotherm and pseudo - second order kinetic .

The thermodynamic parameters were found to be thermodynamically favorable physical adsorption process. Evaluation of thermodynamic parameters showed the process as endothermic and spontaneous. Complete removal of the dye can be achieved using an appropriate dosage of the adsorbent and $\mathrm{pH}$ 7. The results would be useful for the fabrication and designing of wastewater treatment plants for the removal of $\mathrm{RhB}$ dye. Since the raw material is freely available in large quantities the treatment method, seems to be economical.

\section{References}

Al-Fatlawi Alaa Hussein, Mena Muwafaq Neamah (2015): Batch Experiment and Adsorption

Isotherm of Phosphate Removal by Using Drinking Water Treatment Sludge and Red Mud. International Journal of Advanced Research in Science, Engineering and Technology Vol. 2, Issue 3, 557-571.

Abbasi, M. N., and AsI R. (2008): Sonochemical degradation of Basic Blue 41 dye assisted by nanoTiO2 and $\mathrm{H} 2 \mathrm{O} 2$, J. Hazard. Mater. 153, 942-947.

Akash Kumar (2013): Adsorptive removal of Rhodamine B (dye) using low cost adsorbents,M.sc. Thesis, National Institute of Technology, Rourkela, India Amina Boughachiche, Loubna Bouhouf, and Chahrazed Boukhalfa (2015): Characterization of Dyes Adsorption on Carbonized Sewage Sludge. ISSN: 0975-8585, November - December 2015 RJPBCS 6 (6) Page No. 945-952.

Arivoli S., and Thenkuzhali M. (2009): Adsorption of Rhodamine $\mathrm{B}$ by acid activated carbon-kinetic, thermodynamic and equilibrium", Orbital, 2, 2009, 138155.

Balasubramani K. and SIVARA N. (2014): Adsorption Studies of Organic Pollutants onto Activated CarbonInternational Journal of Innovative Research in Science, Engineering and Technology (An ISO 3297: 2007 Certified Organization), Vol. 3, Issue 3, March 2014.

Belala Z., M. Jeguirium, M. Belhachemi, F. Addoun, and G. Trouve (2011): Biosorption of copper from aqueous solutions by data stones and palm-trees waste, Environ. Chem. Lett. 9, no.1, 6569.

Bhatnagar A. and Sillanppa, M. (2010): Utilization of agro- industrial and municipal waste materials as potential adsorbents for water treatment a review,
Chem. Eng. J. 157, 2010, 277-296.19-22.

Biyan J., Fei S., Hu G., Zheng S., Zhang Q., and Xu Z. (2009): Adsorption of methyl tert- butyl ether (MTBE) from aqueous solution by porous polymeric adsorbent. Journal, Hazard material, 161 (1): 81-87.

Bouasla, M.E. Samar, F. Ismail. Degradation of methyl violet $6 \mathrm{~B}$ dye by the Fenton process.Desalination, 254 (2010), pp. 35-41.

Chamargore J. J., Bharad J. V., Madje B. R. and Ubale M. B. (2010): The removal of Dye from Aqueous solution by Adsorption on low cost adsorbents, J. of Chemistry, 7, 3, 1003-1007.

Chen A. H., S. C. Liu, C.Y. Chen and C. Y. Chen (2008): Comparative adsorption of $\mathrm{Cu}$ (II), $\mathrm{Zn}$ (II) and $\mathrm{Pb}$ (II) ions in aqueous solution on the crosslinked chitosan with epichlorohydrin, J. Hazard. Mater. 154, 184-191.

Chowdhury S. and Saha P. (2010): Sea shell powder as a new adsorbent to remove Basic Green 4 (Malachite Green) from aqueous solutions: Equilibrium, kinetic and thermodynamic studies, Chemical Engineering Journal, 164,168-177.

Dabrowski A. (2001): Adsorption-from theory to practice, Adv. Colloid Interface Sci.93 (2001) 135224

Daniel S. and Shoba U. S. (2015): Synthesis, characterization and adsorption behavior of $\mathrm{MgO}$ nano particles on Rhodamine B dye, Journal of Chemical and Pharmaceutical Research, 7(8): 713-723. ISSN: 0975-7384.

Daniela Suteu, Doina Bilba, Carmen Zaharia, and Alina Popescu (2008): Removal of Dyes from Textile Wastewater by Sorption onto Ligno-Cellulosic Materials, Scientific Study \& Research Ix, Issn 1582-540x 293.

Eftekhari S., A. Habibi-Yangjeh, S. Sohrabnezha (201): Application of AIMCM-41 for competitive adsorption of methylene blue and Rhodamine B: Thermodynamic and kinetic studies, J. Hazard. Mater. 178, 349-355.

Fan ,L., Y. Zhou, W. Yang, G. Chen, and F. Yang (2008): Electrochemical degradation of aqueous solution of Amaranth azo dye on AC under potentiostatic model, Dyes Pigments, 76, 440-446.

Gong R., Y. Sun, J. Chen, H. Liu, and C. Yang (2005): Effect of chemical modification on dye adsorption capacity of peanut hull, Dyes and Pigments, vol. 67, no.3, 175-181.

Gunay A., E. Arslankaya, I. Tosun (2007): Lead removal from aqueous solution by natural

and pretreated clinoptilolite: adsorption equilibrium and kinetics, J. Hazard. Mater. 146, 362-371.

Gupta, V. K., A. Mittal, R. Jain, M. Mathur, S. Sikarwar (2007): Photochemical degradation of hazardous dye- Safaranin-T using TiO2 catalyst, J. Colloid. Interface Sci. 309, 460-465.

Gurusamy Annadurai, Ruey-Shin Juang and DuuJong Lee (2002): Use of cellulose-based wastes for adsorption of dyes from aqueous solutions, a Journal of Hazardous Materials B92, 263-274.

llayarajaa M., N. P. Krishnanb, R. Sayee Kannana 
(2013): Adsorption of Rhodamine-B and Congo red dye from Aqueous Solution using Activated Carbon: Kinetics, Isotherms, and Thermodynamics, IOSR Journal Of Environmental Science, Toxicology And Food Technology (IOSR-JESTFT) e-ISSN: 23192402,p- ISSN: 2319-2399. Volume 5, Issue 5 (Sep. - Oct. 2013), PP 79-89.

Inbaraj B. S, and Sulochana N. (2005): Use of jackfruit peel carbon (JPC) for adsorption of rhodamine-B, a basic dye from aqueous solution", Indian Journal of Chemical Technology, Vol. 13, January, 17-23.

Jai S., and Jayaram R. V., (2007): Adsorption of phenol and substituted chlorophenols from aqueous solution by activated carbon prepared from jackfruit (artocarpus heterophyllus) peel- kinetics and equilibrium studies, Sep. Sci. Techn. 42, no. 9, 2019-2032. Kamal S., Ahmed F. E., Hussein F. G., Shokry G. E. B., and Mamdoh R. (2011): Removal of rhodamine B (a basic dye) and thoron (an acidic dye) from dilute aqueous solutions and wastewater simulants by ion flotation", 44, 1449-1461

Kumar K. V. and Porkodi K. (2007): Batch absorber design for different solution volume/adsorbent mass ratios using the experimental equilibrium data with fixed solution volume/adsorbent mass ratio of malachite green onto orange peel, Dyes and Pigments, vol.74, no.3, 590-594.

Lee,J. W.; S. P. Choi; R. Thiruvenkatachari; W. G. Shim; H. Moon. Dyes Pigments., 2006, 69, 196-203. Lee, C. E., Yang, W. F. \& Chiou, S. S. (2006): Utilization of water clarifier sludge for copper

removal in a liquid fluidized-bed reactor. Journal of Hazardous Materials B129, pp. 58-63.

Ma J. W., H. Wang, F. Y. Wang, and Z. H. Huang (2010): Adsorption of 2, 4-dichlorophenol

from aqueous solution by a new low-cost adsorbent-activated bamboo charcoal, Sep. Sci. Tech. 45, no.16, 2329-2336.

Malik P. K., and Saha, S. K. Oxidation of direct dyes with hydrogen peroxide using ferrous ion as catalyst, Sep. Purif. Technol. 31, 2003, 241-250.

Nityanand Singh Maurya, Atul Kumar Mittal and Peter Cornel (2008): Evaluation of adsorption potential of adsorbents: A case of uptake of cationic dyes, 29(1) 31-36.

Rashed M. N. (2011): Acid Dye Removal from Industrial Wastewater by Adsorption on Treated Sewage Sludge', Int. J. Environment and Waste Management, 7, (1/2), 175-191.

Rashed M. N., A. Rashed Mohamed, M. Ahmed Awadallah (2015): Chemically Activated Phosphate Slime as Adsorbent for Heavy Metals Removal from Polluted Water. International Journal of Environment and Waste Management, Vol. 16, No. 2.145-165.

Sachdeva, S. and Kumar, A. (2009): Preparation of nonporous composite carbon membrane for separation of Rhodamine B dye, J. Membr. Sci. 329, 2-10.

Ratnamala G. M. and Brajesh (2013): Biosorption of remazol Navy Blue Dye from an aqueous solution using pseudomonas putida, International Journal of Science, Environment and Technology, Vol. 2, No 1,
$80-89$.

Salleh, M. A. M., D.K. Mahmoud, W. A. W. A. Karim, A. Idris, (2011): Cationic and anionic dye adsorption by agricultural solid wastes: A co prehensive review, Desalination, 280, 1-13.

Srivastava, R. and Rupainwar, D. C. (2011): A comparative evaluation for adsorption of dye on neem and manga bark powder', Indian J. Chem. Technol., vol. 18, pp. 67-75.

Sumanjit and Prasad N. (2001): Adsorption of dyes on Rice Husk Ash, Indian journal of Chemistry-section A, vol.40, no.4, 388-391.

Sumanjit R. K., S. Mahajan, T. P.S. Rani, Walia, and R. Kaur (2010): Adsorptive removal of

five acid dyes using various unconventional adsorbents, Journal of Surface Science and Technology, vol.26, no.1-2, 77-93.

Sun Q. and Yang L. (2003): The adsorption of basic dyes from aqueous solution on modified peat-resin particle, Water Res. 37(7), 1535-1544

Tan, I. A. W., A. L. Ahmad, and B. H. Hameed (2008): Adsorption of basic dye on high

surface area activated carbon prepared from coconut husk: equilibrium, kinetic and hermodynamic studies, J. Hazard. Mater. 154, 337-346.

Vijayalakshmi P., V. S .S. Bala, K. V. Thiruvengadaravi, P. Panneerselvam, M. Palanichamy, and S. Sivanesan, (2011): Removal of acid violet 17 from aqueous solutions by adsorption onto activated carbon prepared from pistachio nut shell, Sep. Sci.Tech. 46, no.1, 155-163.

Wang-Yu Cheng, Ning Li, Yong-Zhang Pan \& LaHua Jin (2016): The Adsorption of Rhodamine B in Water by Modified Zeolites, Modern Applied Science; Vol. 10, No. 5; 2016, ISSN 1913-1844 E-ISSN 19131852, Published by Canadian Center of Science and Education 67.

Weber W., and Morris J., (1963): Kinetics of adsorption on carbon from solution. J. Sanit Eng. Div. Am. Soc. Civ. Eng., 89, 31-60.

Yang, Y.; Tomlinson, D.; Kennedy, S.; and Zhao, Y. Q. (2006): Dewatered alum sludge: a potential adsorbent for phosphorus Removal. Water Science Technology, 54 (5): 207-213.

Zhou Y. F. and R. J. Haynes (2010): Water treatment sludge can be used as an adsorbent for heavy metals in wastewater streams. Waste Management and the Environment $\vee$ 379.379-389.

Zonoozi, M. H., M. R. A. Moghaddam, M. Arami (2009): Coagulation/Flocculation of dye containing solutions using Polyaluminium chloride and alum, Water Sci. Technol. 59, 1343-1351.

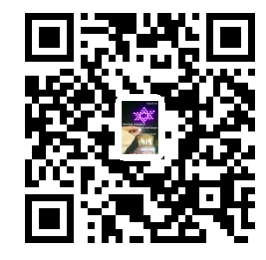

